\title{
İç Oğuza Taş Oğuz Asi Olup Beyrek Öldüğüi Boyu'nda Kozmolojik Yapı ve Ritüel
}

\section{The Cosmological Structure and Ritual in the Legend of the "İç Oğuza Taş Oğuz Asi Olup Beyrek Öldüğü Boy"}

\author{
Ruşen ALIZADE ${ }^{1}$ (1)
}

'Sorumlu yazar/Corresponding author: Ruşen Alizade (Dr. Öğr. Üyesi), İstanbul Aydın Üniversitesi, Fen-Edebiyat Fakültesi, Türk Dili ve Edebiyatı Bölümü, Istanbul, Türkiye

E-posta: rovsenali@aydin.edu.tr ORCID: 0000-0002-0561-8294

Başvuru/Submitted: 11.12.2020 Revizyon Talebi/Revision Requested: 02.02.2020

Son Revizyon/Last Revision Received: 22.03.2021

Kabul/Accepted: 23.03 .2021

Online Yayın/Published Online: 06.05.2021

Atıf/Citation: Alizade, Rusen. "iç Oğuza Taş Oğuz Asi Olup Beyrek Öldüğü Boyu'nda Kozmolojik Yapı ve Ritüel." Türkiyat MecmuasıJournal of Turkology 31, 1 (2021): 47-61. https://doi.org/10.26650/iuturkiyat.838620

\section{Öz}

Türk kültürünün görkemli ve benzersiz eseri olan Dede Korkut Kitabı'nın bünyesinde çok sayıda mitolojik öge, kozmolojik model, ritüel, motif, karakter, atasözü ve deyimin bulunduğu bilinmektedir. Oğuz topluluğunun kahramanlık destanı olarak tanımlanan söz konusu eposun sonuncu boyundaki tematik yapıya dayanılan bu çalışmada, bazı yapısal anlam birimler, özellikle kozmolojik yapı, tematik bağlam, karakter ve ritüel gibi olgular ele alınıp tahlil süzgecinden geçirilmiştir. Çalışmada, Dede Korkut Kitabı'nın Dresden nüshasının Orhan Şaik Gökyay neşri esas alınmış ve bu neşirdeki sonuncu boy (íç Oğuza Taş Oğuz Asi Olup Beyrek Öldüğü Boyu), semantik açıdan irdelenmiştir. Sonuncu boyun kapsamlı bir irdelenmeye tabi tutulması sonucu tespit edilmiştir ki boyda görülen karşıtlık olgusu, aslında kapsam ve etkisine göre eposun herhangi bir boyunda bulunan zıtlıkla karşılaştırılamaz niteliktedir. Araştırmada söz konusu boya yansımış Oğuz töresinin veya Oğuz topluluğunun varoluş ilkesinin önemini belli eden olaylar dizisi betimsel çözümleme ile değerlendirilmiş ve İç Oğuz ile Taş Oğuz arasında oluşan düşmanlığın nedeni net olarak belirlenmiştir.

Anahtar kelimeler: Yağma töreni, Karşıtlık, Tematik yapı, İç Oğuz, Taş Oğuz

\section{ABSTRACT}

A wide variety of mythological elements, cosmological models, rituals, motifs, characters, proverbs, and idioms appear in The Book of Dede Korkut, a unique work and signature of Turkish culture. This study investigates the thematic structure of the last legend of the work, a heroic epic of the Oghuz community. Some structural morphemes, including cosmological structures, thematic contexts, character, and ritual were passed through the filter of analysis. The Gökyay publication of the Dresden copy of The Book of Dede Korkut was taken as the basis for this study, and the final legend (The Story of the Revolt of the Outer Oghuz against the Inner Oghuz and of the Death of Beyrek) in this text is semantically analyzed. The comprehensive analysis of this legend indicates that the phenomenon of opposition developed in the legend is, in fact, not comparable to any legend of the epos in terms of its scope and effect. The series of events that ground the Oghuz tradition or community as reflected in the legend is evaluated through descriptive analysis, and the reason for the hostility between Inner Oghuz and Outer Oghuz is clearly established.

Keywords: Plunder ceremony, Contrast, Thematic structure, Inner Oghuz, Outer Oghuz 


\section{EXTENDED ABSTRACT}

The plunder ceremony described in the prelude section of the last legend of The Book of Dede Korkut indicates an epic contrast in the content of the legend. The thematic structure of the last legend includes several contrasting phenomena. These developed into qualified elements of epos and existed as double reflection styles, especially in the layers of the final legend. This study examines this double structure in detail, and its findings on its formation are supported by reference to the views of other researchers. The points in the tale where Khan Kazan and Aruz Koja change places with three other characters are evaluated using diagrams, as are other questions related to these issues. In addition to determining the paradigms where contrasting phenomena can be deployed, the effects and functions of the phenomena for eliminating these contrasts are also addressed in the study. Furthermore, it is emphasized that the contrasting phenomena in question are opposition or internal conflict within the ethnos, and it is determined that this conflict the result of the deterioration of the structure of the Uch Ok (Three Arrows) and the Boz Ok (Gray Arrow) traditions.

Additional determinations also appear in the course of investigating the events that take place in the last legend and the identity and status of the characters included in these events. In particular, it is ascertained that Bayindir Khan and Salur Kazan in particular, among the characters reflected in the legend, do not possess the authority to rule over the Galin Oghuz (Eli). In fact, someone from the Boz Ok, such as Aruz Koja, has the right, according to the traditional structure. Another important finding is that although Aruz Koja plays the role of a defender of neglected customs, he is altered into an anti-hero. The political order that dominates the final legend is, in fact, an anti-structure that goes against custom, and the disruption of the sharing principle is directly caused by the anti-structure in question. In this study, it is also determined that the epic contrast that is reflected in the last legend is resolved through the contrasting phenomenon of the victory of Kazan. Here Aruz becomes the representative of chaos.

A still more important finding is that the thematic structure of the last legend has sub-textual elements as well as a second full thematic structure. The morphemes that possess a nonlogical character rather than contrasting elements relate to the message underlying the text and the second structure are also determined in the study. In this context, Aruz Koja is confirmed to be the inheritor of political sovereignty, based on the traditional order, primarily seen in the subtext. In this determination, it can be seen that the real status constituted a contradicting phenomenon with the traditional status of subtext. At the same time, it is noted that the terms Uch Ok and Boz Ok, as elements, relate primarily to the second thematic context, and this second thematic structure is also subjected to a transformation. In this context, it can be hypothesized that the terms Uch Ok and Boz Ok are the older versions of the titles of Inner Oghuz and Outer Oghuz factions. The second relevant morpheme is related to the fact that Aruz Koja is a hero before the beginning of the legend and has the form of an anti-hero at 
its end. However, this is determined from the sub-textual structure and the second thematic structure. Aruz Koja maintains a heroic status until the end of the legend in the surface layer.

The Outer Oghuz lords and Aruz Koja, who does not participate in the plunder ceremony depicted in the legend, take a hostile attitude toward Khan Kazan. In the study, it is found that Aruz still maintains the heroic status until this stage, and it is seen that the first and second thematic structures in this legend do not constitute a contrast until this stage. It is clearly emphasized that Aruz Koja has a respectable place and position in the Oghuz community until the moment in question, and Kazan is considered to be an anti-hero who disrupts the integrity of the society during this stage. The murder of Beyrek, advisor to Kazan, by Aruz, is described later in the study, and this incident is judged to be the factor that leads directly to the punishment of Aruz. It is also established that certain types of conduct that attracts attention in the narrative after the deterioration of the plundering tradition indicates Kazan's status as an anti-hero in a superficial manner. In this regard, it appears that the status change between Kazan and Aruz is related to the murder of Beyrek.

It is determined that the thematic structure in the final legend is directly related to the ritual-mythological layer, and a new independent element is formed in the structure of the legend. The ritual phenomenon reflected in the prelude section to the twelfth legend is also examined, and it was established that this phenomenon shows the unchanging structure of the functionality and semantics of the Oghuz community. It can be seen that ritual phenomena are reflected in the thematic structure, and, with this, a reflection from holy to profane phenomena can be recognized in the epic narration. This becomes evident at the end of the legend, as the phenomenon in question is displaced. The displacement event can be confirmed by examining the ritual of remarking performed by Dede Korkut.

In this study, it is determined that the structure in the last legend of The Book of Dede Korkut is ritual-mythological, and it is shown that the structure of the legend is, in fact, a variant and reflects the structure of the ritual. Therefore, it is noted that the micro-thematic order, dealt with in the last legend, reflects the ritual-mythological invariance in relation to schemes that display functionality, and it is determined that ritual is present in the subtext of the last legend of The Book of Dede Korkut. 


\section{Giriş}

Dede Korkut Kitabı'nın tematik yapısı (mesaj-düşünce ve duygu oluşumu), Oğuzluk

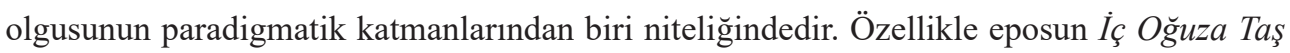
Ŏguz Asi Olup Beyrek Öldügü Boyu'ndaki tematik yapının göstergebilimsel-işlevsel inceleme açısından ele alınıp değerlendirilmesi için söz konusu boyun muhtevasında gereken malzeme ve ögelerin bulunduğu söylenebilir. Sonuncu boydaki tematik yapı ele alınıp incelenmeden önce, bu yapının oluşmasına neden olan kronotopun (mekân-zaman birlikteliğinin) dizimsel sürekliliğe göre, yani, kişi-olay düzenliliği bakımından gözden geçirilmesi gerekir. Bu düzenlilik net olarak şöyledir: Üç Ok ve Boz Ok bir araya geldiği zaman Han Kazan evini yağmalatırdı. Yağma töreni yine gerçekleşir, ancak yağma eylemine yalnız İç Oğuz beyleri katılır. Aruz Koca'nın başlarında bulunduğu Taş (Dış) Oğuz beyleri yağmada bulunmazlar. Taş Oğuz beyleri hakarete maruz kaldıklarını düşünerek Han Kazan'a düşman olurlar. Taş Oğuzların kendisini selamlamaya gelmediğini fark eden Han Kazan, Taş Oğuzların dost mu, düşman mı olduklarını anlamak için Kılbaş'ı Taş Oğuz beyleri tarafına gönderir. Aruz Koca, yağmada bulunmadıklarını ve Kazan'a düşman olduklarını Kılbaş'a söyler. Aruz Koca, yığanak düzenler, Taş Oğuz beylerini ağırlar ve onları Kazan'a düşman olmaları için Kuran-ı Kerim üzerine yemin ettirir. Aruz Koca, Taş Oğuzdan evlenen ancak Han Kazan'ın divanında görevde bulunan Beyrek'i çağırttırır ve kendilerine katılmayı teklif eder. Beyrek bu teklife karşı çıkar ve Aruz onu öldürür. Beyrek'in ölüm haberi Kazan'a ulaşır ve İç Oğuz beyleri Beyrek'in öcünü almaya karar verirler. İç Oğuzla Taş Oğuz arasında savaş olur. Aruz Koca’nın başı kesilir, Taş Oğuz beyleri Han Kazan'ın ayağına düşüp af dilerler. Kazan onları affeder. Han Kazan, elde ettiği zaferi kutlar: "Kazan gök alan görklü çemene çadır dikdürdü, otağın kurdu. Dedem Korkud gelüben şazılık çaldı, boy boyladı, soy soyladı."

\section{Sonuncu Boyun Kozmolojik Yapısı}

Öncelikle denilebilir ki İç Oğuza Taş Oğuz Asi Olup Beyrek Öldüğ̈̈ Boyu 'ndaki unsurlar dizisi, epik bir karşıtlığa dayanmaktadır. Şöyle ki söz konusu boyun giriş kısmında Oğuz ilinin her iki kolunun (Üç Ok/İç Oğuz ve Boz Ok/Taş Oğuz) katılımıyla gerçekleşen yağma töreni anlatılmaktadır. Bu tören, Han Kazan'ın evinin İç Oğuz ile Taş Oğuz bir araya gelince yağma edilmesi olayıdır ki bir sonraki zaman diliminde tekrar gerçekleşmekte ve törenden sorumlu Han Kazan, Taş Oğuzların törene katılımını sağlamamaktadır. Böyle bir ortamda Han Kazan'ın onayıyla Taş Oğuz beylerinin hakları bozulur ve Aruz Koca'nın mevcut duruma karşı çıkmasıyla hem Taş Oğuzların, hem de tüm Oğuz ilinin varoluşundaki önemli bir ilke savunulmuş olur. Genellikle sonuncu boy, epik karşıtlığın gerçekleşmesi bağlamında oluşmaktadır. Bu karşıtlık, epik yapının nitelikli unsurlarından biri olarak eposun birkaç katmanında çift yansıma şekilleri gibi de yer almaktadır.

1 Orhan Şaik Gökyay, Dedem Korkudun Kitabı (İstanbul: Kabalcı Yayınevi, 2006), 193. 
Düalizm (ikilik), kozmolojik düşüncenin yapısıyla ilgili olduğu için mitolojik dünya modeli bir düalite ile ortaya çıkar. Bu durumda üzerine eğildiğimiz epos, yapısal düşünceyi gerçekleştiren metin olarak söz konusu ikiliyi çeşitli aşamalardan sürekli yansıtmaktadır. Kamal Abdulla, Dede Korkut Kitabı 'nın Poetikasına Giriş Şafak Varyantı adlı eserinde eposun sekizinci boyunda görülen ikili karşıtlıklar hususunda şöyle yazmaktadır: "Bu münasebetle Dede Korkut Kitabı ’nın Basat Tepegöz'ü öldürdüğü boy”a dikkat çekmek isteriz. Biz “doğamedeniyet" gibi en eski dikotomilerden (ikili karşıtlıklardan) birinin açık bir anlatımıyla özellikle bu hikayede karşılaşırız. İşte bu olgu, bilhassa kozmolojik (tarih öncesi) çağın izlerinin Dede Korkut Kitabı 'nda yaşadığının açık bir örneğidir."2

Ele alıp incelediğimiz on ikinci boyun tematik yapısı da birbirine karşıt olan ikiliklerin dizimsel yapısını kozmolojik düzen tutarlılığına uygun bir şekilde yansıtabilmektedir. Şöyle ki dost-düşman, Üç Ok-Boz Ok, İç Oğuz-Taş Oğuz, Han Kazan-Aruz Koca, Kılbaş-Aruz Koca ve Beyrek-Aruz Koca gibi karşıt olgular, insan-insan ve etnos-etnos katmanlarını kapsayan statü niteliğindeki zıtlıklar sayılmaktadır. Karşıt unsurlar, tematik yapının çift yapısına göre ele alındığı zaman bu hususta ikili yapı, sürekli üç unsurun iki yön oluşturmasıyla gerçekleşebilir:

a. Birinci yönün unsurları: $\ddot{U} c ̧$ Ok (İç Oğuz), Han Kazan;

b. İkinci yönün unsurlarl: Boz Ok (Taş Oğuz), Aruz Koca;

c. Meditasyon işlevini yerine getiren unsurlar: Kılbaş, Beyrek.

Çift opozisyonlara (karşı etki gösterme durumlarına) dair Victor Turner ve Lévi-Strauss'un bakışlarını aynı konuma getirdiğimiz zaman, bazı durumlarda üç unsurun iki yönlü karşıtlık oluşturduğu net olarak belirlenebilir. Turner, ilkel kültür bağlamında türlerin renk sembolizmini ele alıp "Yalnız cinsi ikilikleri değil, aynı zamanda kuramsal olmayan ikiliklerin herhangi bir şeklini, pek geniş bulunan üç üyeli sınıflandırmanın temeli gibi almak gerekir" der. ${ }^{3} \mathrm{Bu}$ tespite dayanarak söylemek mümkündür ki ikili yapılar üç üyeli (unsurlu) ve iki yönlü olabilir. Ayrıca Turner, karşı etki gösterme durumlarının temel unsurlarını doğru bir şekilde tanımlamış olsa da, aynı unsurların sintagmatik (dizimsel) sırasının işılevsel yapısını belirlememiştir. Araştırmacı, paradigmatik sembolleri belirleyip eşzamanlı unsurları dizmişse de işlevsel devinimin (sintagmatik hareketin) eşzamanlı ve artzamanlı yönlerinin ilişsisinden söz etmemiştir. Lévi-Strauss'a göre, ilk opozisyonun istenilen ikilisi, ikinci bir ikiliyi ve daha sonra üçüncü bir ikiliyi vs. türetebilir. ${ }^{4}$ Görülmektedir ki yapının Turner betimlemesiyle (İngiliz sosyal antropolojisiyle), Lévi-Strauss betimlemesi (Fransız yapısalcılığı) denkleşmemektedir. Oysa her iki araştırmacının bakış açıları çift yapının belirli katmanında birbirine denk gelen görüşler niteliğindedir.

2 Kamal Abdulla, Dede Korkut Kitabı'nın Poetikasına Giriş Şafak Varyantı, çev. Ali Duymaz (İstanbul: Ötüken Yayınları, 2020), 20.

3 Viktor Terner, Simvol i Ritual (Moskova: Nauka, 1983), 71.

4 Klod Levi-Stross, “Mif-Ritual-Genetika”, Jurnal Priroda 1, (1978): 90-106, 93. 
Lévi-Strauss, Strukturnaya Antropologiya (Yapısal Antropoloji) adlı eserinde ise şöyle yazmaktadır: "Mit, genelde karşıtlıklarla işlem yapar ve meditasyona, yani karşıtlıkların git gide ortadan kaybolmasına çalışır. Örneğin, birinden diğerine geçişi mümkün olmayan iki üye, eşdeğer olan başka iki üyeyle yer değiştirir. Bunlar da üçüncü bir üyeyi, geçiş üyesini kasteder. Bu durumdan sonra dışa değgin bir üye ve mediator (arabulucu), bir diğer triada (üçlü) ile yer değiştirebilir." 5

Lévi-Strauss'un mitin işlevsel yapısını açıklayan yukarıdaki fikirlerinden anlaşılmaktadır ki mit, daha sert karşıtlıkların daha uygun zıtlıklarla yer değiştirmesini sağlamakla çözüme doğru yönelmektedir. Şöyle ki sert karşıtlı iki direniş sergileyen üye, yeni iki üyeli çiftle yer değiştirir. Ancak bu iki üyeli ikilik, kendi yapısında artık üç üyeli niteliktedir. Yani, karşı olan yönlerden biri çift yönlü olmakla üçlü model oluşturmaktadır. Üçlü üyelerden biri arabulucudur ve bu üye direnen veya karşı gelen üyeler arasında irtibat sağlayabilir. Denilebilir ki mitin Lévi-Strauss tarafından çözümlenen söz konusu yapısı evrensel bir nitelik taşımaktadır. Kaydedilen husus, Dede Korkut Kitabı'nın sonuncu boyundaki tematik yapıda da görülmektedir. Sonuncu boydaki karşı etki gösterme durumunun sert karşıtlık bağlamında bulunan iki baş üyesi veya unsuru ise İç Oğuz ve Taş Oğuzdur. Bu olgular, Han Kazan ve Aruz Koca gibi karşıt dikotomiyle (ikilikle) yer değiştirebilir. Ancak, bu ikilik kendi bünyesinde trikotomidir (üçlüktür):

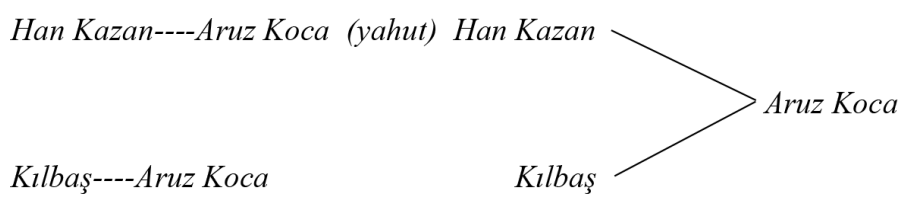

Görüldüğü gibi Han Kazan ve Aruz Koca ikilisi, üçlükle (Kazan-Kılbaş-Aruz) yer değiştirmektedir. Bu duruma rağmen yine üç üye, ikilikte olduğu gibi iki yön oluşturabilir. Kılbaş, arabulucu üye statüsünde Kazan'dan yana olur. Kılbaş'ın arabuluculuğu ise gerçek nitelikte değil, yalan paradigmasında bulunan bir olgudur. Kılbaş'ın Aruz Koca'ya uğrayıp Han Kazan'ın üzerine düşman geldiğini demesi ve Kazan'ın Aruz'dan yardım istediğini anlatması olayı aslında bir yalandan ibarettir.

Lévi-Strauss'a göre, birinci, ikinci, üçüncü vs. dereceli mediatorları (arabulucuları) eklemek mümkün olabilir, yani opozisyon ve korelasyonların (bağlılaşımların) yardımıyla her üyeden yeni bir üye türetmek mümkündür. ${ }^{6}$ Bu husus, sonuncu boy metni kapsamında küçük bir detay konumunda da olsa Han Kazan'ın kardeşi Kara Güne'nin arabuluculuğunda görülmektedir. Boyda Aruz Koca, yalancı meditasyon (barışık) bahanesiyle Beyrek’i çağırttırır ve Beyrek bu davete icabet eder. Bu durumda Kılbaş'ın arabuluculuğu Beyrek'in arabuluculuğuyla yer değiştirmektedir. Beyrek öldürülür ve onun öldürülme nedeni bağlılaşım göstergesi olarak bir sonraki üçlüyü türetebilir. Beyrek'in öldürülmesi olayından sonra Han Kazan

$5 \quad$ Klod Levi-Stross, Strukturnaya Antropologiya (Moskova: Nauka, 1985), 201.

6 Levi-Stross, Strukturnaya Antropologiya, 201. 
odasına kapanır, yedi gün divana çıkmaz. Bu durumda Kara Güne, Kılbaş’ın Kazan'a gidip onu çağırması gerektiğini söyler (yani Kılbaş’ın Kazan'la İç Oğuz arasında arabuluculuk yapmasını ister). Kılbaş ona itiraz edip "Sen karındaşısun, sen var"” demektedir. Böylece, Beyrek'in öldürülmesi olayı, Han Kazan-İç Oğuz karşıtlığını ortaya çıkarmaktadır (bu karşıtlık metinde pek abartılı nitelikte değil, daha fazla metin altıyla ilgili olup ikinci tematik bağlam katmanından kaynaklanmaktadır). Yani görülen karşıtlık, İç Oğuz’un içerisine yansımaktadır. Bu karşıtlığın ortadan kaldırılması için arabulucuya ihtiyaç vardır. İşte bu husus, bir sonraki iki yönlü üçlüğü türetebilir:

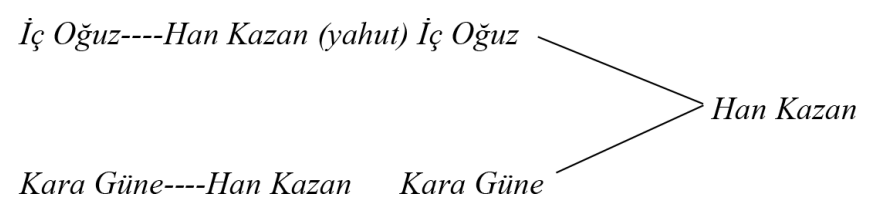

Böylece, eposun İç Ŏguza Taş Ŏguz Asi Olup Beyrek Öldüğü Boyu'u, çift karşıtlıkların sentaktik sırası niteliğinde oluşabilir. Aslında bu durumda art arda gelen olguların bir dizi oluşturduğu görülmektedir. Bu dizinin halkaları ikiliklerdir. Bir ikilikten diğerine geçiş, mediator üyeler aracılığıyla gerçekleşmektedir. Söz konusu geçiş aşamasında, ikiliğin herhangi bir üyesine yeni bir üye -arabulucu- eklenmekte ve diğer bir üyenin durağan nitelikte kaldığ dikkat çekmektedir. Denilebilir ki geçişin her basamağı, üç üyeyi (iki karşı bulunan üyeyi) ve onlardan herhangi birinden yana olan arabulucuyu kastetmektedir. Şöyle ki çift olgular, "tematik zincire" bağlılaşım çubuğuyla dizilmektedir. Bu açıdan, İç Oğuz ile Taş Oğuz arasındaki karşıtlık veya sosyal-kozmik düşmanlık, tematik yapıdaki ikilikleri birbiriyle birleştirebilen bağlılaşım göstergelerine dönüştürmektedir. Görülmektedir ki çift karşıtlıklar, tematik yapının giriş kısmından sonuna kadar kaydedilen bağlılaşım göstergelerinin (İç Oğuz ile Taş Oğuz arasındaki statü, egemen olma vs. zıtlıkların) sıralanmasına olanak tanımaktadır.

\section{Tematik Yapının Kozmolojik Semantiği}

Ele alıp incelediğimiz sonuncu boydaki tematik yapıya yansımış karşıtlık olgusu, etnos içi bir karşıtlık veya iç çatışmadır. Şöyle ki Han Kazan ile Aruz Koca arasında oluşan düşmanlığın İç Oğuz ile Taş Oğuz arasında bir iç çatışmaya dönüştüğü görülmekte ve bu çatışmanın temelinde Üç Ok ve Boz Ok töre yapısının bozulduğu gerçeği bulunmaktadır. Denilebilir ki sonuncu boydaki epik çatışmanın temelinde bulunan neden, doğrudan Oğuz topluluğunun varoluşunda önemli ilkelerden biridir. Söz konusu epik çatışma, olumlu bir şekilde çözülmezse Oğuz topluluğu ciddi bir zedelenmeye maruz kalır, hatta yok olabilir. Şu gerçeğe de önem vermek gerekir ki eposun herhangi bir boyunda bulunan karşıtlık olgusu, kapsam ve etkisi bakımından sonuncu boydaki zıtlıkla karşılaştırılamaz boyuttadır. Aslında ele alınan husus,

7 Gökyay, Dedem Korkudun Kitabı, 192. 
Oğuz topluluğunun varoluş ilkesi veya törenin en önemli yasası meselesidir. Bu açıdan, genel bir sorun niteliğinde görülen karşıtlık olgusu ele alınıp incelenirken, öncelikle Türk etnik kültürel bağlamında bulunan en eski etno-psikolojik davranış kalıpları değerlendirilebilir. Dolayısıyla Türk töre ilkelerine aykırı olan normalden uzaklaşma durumlarına ilişkin çeşitli görüşler de ileri sürülebilir.

Dede Korkut Kitabl'nda siyasi hakimiyeti sembolize eden Bayındır Han ve Salur Kazan, Üç Oklara mensup kişilerdir. Ancak Oğuz il geleneğine (töreye) göre bu kişilerin Kalın Oğuzun (Oğuz devletinin) başına egemen olma yetkileri bulunmamaktadır. Aruz Koca ise Boz Oklardandır ve siyasi egemenlik yine töresel yapıya göre onun veya Boz Okların hakkıdır. Eposa yansıyan siyasi düzen ise töreye aykırı bulunan bir anti-yapıyı içermektedir. Bu durum, daha net bir şekilde aşağıdaki 1. şemada görülmektedir:

1. ŞEMA

\begin{tabular}{|c|c|c|}
\hline Yöneten & Han Kazan & Aruz Koca \\
\hline Töre gereği & Üç Ok (vasal) & Boz Ok (egemen) \\
\hline Gerçek statü & İç Oğuz (egemen) & Taş Oğuz (vasal) \\
\hline
\end{tabular}

Böylelikle, söz konusu karşıtlık, törenin ve Oğuz Kağan’ın oluşturduğu Boz Ok-Üç Ok egemenliğinin önemli bir ilkesinin - paylaşım ilkesinin - bozulmasıyla ilgilidir. Bu bakımdan Aruz Koca, bozulan törenin savunucusu gibi rol üstlenir. Ancak görülmektedir ki ele alınan karşıtlığın epik çözümü yine karşıt bir olguya dayanmaktadır. Yani, Aruz'un kozmik düzenin savunucusu konumunda bulunmasına rağmen, epik karşıtlık, Kazan'ın elde ettiği zaferle çözülmekte ve Aruz, anti kahramana dönüştürülmekte veya kaosun temsilcisi konumuna getirilmektedir. Denilebilir ki sonuncu boy, basit bir tematik yapı içermiş olsa da, semantik yapısına göre basit olmayan boy niteliğinde görülmektedir. Bu açıdan, boydaki tematik yapının hem metin altı bağlam bakımından hem de ikinci tematik yapı katmanına göre semantik bir irdelenmeye tabi tutulması gerekmektedir.

Boris Nikolayeviç Putilov, Geroiçeskiy Epos i Deystvitelnost (Kahramanlık Destanı ve Gerçeklik) adlı eserinde epik tematik yapının çok boyutluluğunu sağlayan metin altına dair şöyle yazmaktadır: "Metin altı, bizi epik ilişkilerin genel formüllerine doğru götürür: Bu özellik, kahramanların davranışında makul görülmeyen epik mantığı ve değeri açıklar; tesadüfi ve ilginç görünenin aslında olağan olduğunu, ani bir değişiklikle ortaya çıkmış gibi düşünülenin de, içsel bağımlılık ilkelerini tespit eder; kahramanın kaderinin epik izlencesini, önceden belirlenmiş ve önünün kesilemez olduğunu açıklar."

Putilov, ikinci tematik yapının ise anlatı geleneğinin dönüşümler bağlamında ortaya çıktığını söylemekte ve bu süreçte eski temaların yeni tematik yapılar bünyesinde motifler, motif blokları ve halkalar gibi bulunabildiğini yazmaktadır. ${ }^{9}$ Araştırmacının görüşünde, herhangi bir anlatı geleneğinin gelişmesi için sözlü anlatımın yeni tematik yapısal aşamalara aktarılmasının da

8 Boris Nikolayeviç Putilov, Geroiçeskiy Epos i Deystvitelnost (Leningrad: Nauka, 1988), 177.

9 Putilov, Geroiçeskiy Epos i Deystvitelnost, 193. 
kaçınılmaz olduğu hususu yer almaktadır. Bu durumda tematik yapının bir önceki aşamaları, belirlenmiş unsurlarıyla birlikte yeni tematik yapıda varlığını sürdürebilmekte ve bu varoluş, ilk tematik yapıda ikinci tematik yapıyı oluşturabilmektedir.

Dede Korkut Kitabı'nın sonuncu boyundaki tematik yap1, hem metin altı ögelere, yani, tema birlikteliğinin saklı kalan nedenlerine hem de söz konusu tematik yapının retrospektif (geriye bakılabilen) aşamasına (ikinci tematik yapıya) sahip olabilmektedir. Aynı zamanda, vurgulanan yapı altında pek dikkat çekmeyen tematik katmanlar da bulunmaktadır. Bu açıdan, sonuncu boydaki tematik yapının kozmolojik semantiği belirlenirken doğrudan metin altı ve ikinci tematik yapının da onarılması gerekmektedir. Sonuncu boyda dikkat çeken tematik yapı, metin altı anlam ve ikinci tematik yapıyla ilgili bir hayli epik unsuru ve karşı ögeleri bünyesinde taşımaktadır. İlk gözlem zamanı basit görülen bu yapıda, tematik yapısal olaylar bakımından uygun olmayan ve mantık dışı olarak algılanan semantik unsur ve işlevler de yer almaktadır. Söz konusu unsur ve işlevler, aşağıdaki bölümde ele alınıp incelenecektir.

\section{1. Tematik Yapıda Bulunan Mantık Dışı Semantemler}

Bu bölümde ele alacağımız semantemlerden (anlam birimlerden) birincisi, sonuncu boyun tematik yapısında görülen epik karşıtlıktır. Bu karşıtlık, doğrudan Üç Ok ve Boz Okla ilgili töresel düzenin bozulmasından kaynaklanmaktadır. Sonuncu boyda Aruz Koca'nın Han Kazan'a düşman olması olayı, metin altında bulunan töresel düzenle ilgilidir. Aruz Koca, siyasi egemenliğin töresel yasalar gereğince mirasçısıdır. O, Han Kazan'ın Kalın Oğuz başında bulunmasından memnun değildir veya Kazan'ın yerine kendisinin layık olduğunu düşünmektedir. Bu durumda metin altı töre statüsüyle gerçek statünün karşıtlığı ortaya çıkmaktadır. Aynı zamanda, eposun daha önceki boylarında bir kez bile geçmeyen Üç Ok ve Boz Ok gibi tabirlerin, sonuncu boyun ele alınan tematik bağlamından ziyade ikinci tematik bağlamıyla ilgili unsurlara dönüştüğü görülmektedir. Üç Ok-Boz Ok etnonimlerinin (ulus veya kavim adlarının), İç Oğuz ile Taş Oğuz tirelerinin daha eski adları olduğu kanısı ise boyun muhtevasına dayanılarak söylenebilir. Üç Ok-Boz Ok etnonimleri, uygun bir biçimde İç Oğuz-Taş Oğuz kavramlarına dönüştüğü için bunların bulunduğu tematik yapılar da bir dönüşüme maruz kalmışlardır.

İkinci olağandışı semantem, Aruz Koca'nın boy öncesi kahraman, boy sonunda ise antikahraman durumunda olması gerçeğiyle ilgilidir. Şöyle ki her iki Oğuz kolunun (Üç Ok ve Boz Ok'un) başında bulunan Han Kazan, Kalın Oğuzun birlik ve beraberliğini sağlamayı başarabildiği halde, bilerek yağma törenini bozar. Töreye göre Kazan'ın bu adımı, Kalın Oğuzun bütünlüğünü bozmaktadır. Aruz Koca, bu olaya karşı olmakla törenin ve Kalın Oğuz birliğinin koruyucusu gibi rol üstlenmektedir. Buna karşılık boyun sonunda Aruz'un cezalandırılması söz konusudur. Oysaki epik mantığa göre Kazan’ın cezalandırılması gerekirdi. Bu durum, epik karşıtlık oluşturmaktadır. Ortaya çıkan karşıtlık nedeniyle doğal olarak şöyle bir soru sorulabilir: Neden Oğuz töresinin savunucusu veya epik normların kaynaklandığı Oğuz hafızasının koruyucusu 
cezalandırılır? Bu soruya cevap olarak söylenebilir ki betimlenen durumun ilk tematik yapıdaki motife bürünmüş mantığı, pek etkisiz ve aykırı düşünce niteliğindedir. Görülmektedir ki metin altı ve ikinci tematik yapı, aslında Aruz Koca'yı boyun sonuna kadar kahraman statüsünde bulundurmaktadır. Bu duruma ilişkin daha net tespitler ise aşağıdaki kısımlardadır.

Bütün Oğuz topluluk üyelerinin en önemli yağma törenine katılımları sağlanmadığı için Aruz Koca ve arkasındaki Taş Oğuz beyleri, Han Kazan'a karşı düşmanca bir tavır almaktadırlar. Bu olay sonrası Kılbaş ile Beyrek, İç Oğuz ile Taş Oğuz arasında arabuluculuk yaparlar. Böyle bir ortamda veya ilk meditasyon katmanında Aruz Koca, henüz kahraman statüsündedir. Şöyle ki bu aşamaya kadar birinci ve ikinci tematik yapının herhangi bir karşıtlık oluşturmadığı dikkat çekmektedir. Bu bağlamda Alp Aruz, metin altı mantıkta ve ikinci tematik yapıda kahraman veya etno-kozmosun koruyucusudur. Han Kazan ise toplumun bütünlüğünü bozan bir figürdür. $\mathrm{Bu}$ durumda özellikle Beyrek'in arabuluculuğu sayesinde ikinci tematik yapı ilkinden ayrılmaktadır. İkinci tematik yapının daha alt katmana sirayet edip sadece kırıntı şeklinde ara sıra dikkat çektiği söylenebilir. Beyrek’i öldürmesiyle Aruz, anti-kahraman statüsüne sahip olur. Bizzat bu durum, aşağıda aktarılan hususlar sonucunda netlik kazanmaktadır.

Sonuncu boyda Beyrek, aynı zamanda Han Kazan'ın ınağı olarak betimlenmektedir. Yani, Beyrek, ciddi bir mevki sahibidir. Bu açıdan Beyrek'in öldürülmesi olayı, Aruz'un cezalandırılmasına yol açan en önemli etkendir. Beyrek, ölmeden önce intikamının alınması için Han Kazan'a vasiyette bulunur. Doğrudan bu hususta Kazan ve Aruz'un statülerine ilişkin ikili bir ilintinin ortaya çıktığı görülmektedir. Kazan ve Aruz'un statüleri bu bağlamda değişmektedir. Söz konusu değişikliğe dair bazı hususları metinden verilen alıntılara göre belirlemek mümkündür. Şöyle ki Beyrek'in ölüm haberini alan Kazan, yedi gün gözyaşları içerisinde yas tutar ve odasına kapanır. Bu durumda kardeşi Kara Güne'nin dediği sözler dikkat çekmektedir. O, Kılbaş’a şöyle söyler: "Kılbaş, var ayıt, ağam Kazan gelsün, çıksun. Bir yigit senün ucundan aramuzdan eksildi." ${ }^{10}$ Kılbaş, metnin ilk tematik yapısında doğrudan görülmeyen nedenlere göre bu sözleri Kazan'a tek başına söylemeye cüret etmez ve ona şu cevabı verir: "Sen karındaşısun, sen var." "Her ikisi (Kara Güne ve Kılbaş) birlikte Kazan'ın odasına gider ve söylerler: "Bir yigid aramuzdan eksildi, senün yolunda baş verdi. Dirim kanın alalum, hem size 1smarlamış, menüm kanum alsun, demiş." 12

Görüldüğü gibi her iki Oğuz yiğidi, Beyrek'in Kazan uğruna can verdiğini söylerler. Bu hususta birbirine paradigmada bulunan ve Kazan'ın konumuna ilişkin bağlılaşım okuyla birleşen aşağıdaki ikilikler de dikkat çekmektedir:

10 Gökyay, Dedem Korkudun Kitabı, 192.

11 Gökyay, Dedem Korkudun Kitabı, 192.

12 Gökyay, Dedem Korkudun Kitabı, 193. 


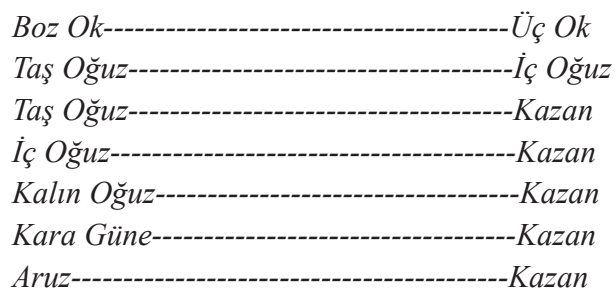

Bu karşıt yapıda, İç Oğuz-Taş Oğuz çatışması ile İç Oğuzun içerisindeki içsel çatışma birbiriyle ilintili durumdadır. Kazan'ın yanlış gibi görülen adımı, aslında İç Oğuzun töresel yapıya dayanılmayan egemenliğini etkin kılmaya yönelik olan gövde gösterisidir ve bu husus, var olan Kalın Oğuz ilinin parçalanmasını da beraberinde getirmektedir. Kalın Oğuzun var olduğu ortamda Üç Okların iktidarda bulundukları görülmektedir ki Boz Oklar, bu durumu istemeseler bile kabullenmişlerdir. Böyle bir ortamda güce dayalı kozmik bir düzenliliğin varoluşu da dikkat çekmektedir. Yağma geleneğinin bozulmasıyla doğal olarak var olan kozmik düzen de bozulmuş olur ve bu durumda Kazan'ın kardeşi Kara Güne’nin bağlamsal davranışı Aruz'un tutumuyla denk gelmektedir. Her iki alp (Kara Güne ve Aruz), çeşitli katmanlara bağlı olarak törenin savunucuları gibi davranmaktadırlar. Bu tür bağlamsal davranışlar, yüzeysel bir şekilde de olsa, Kazan'ın anti-kahraman statüsünü sezdirmektedir. Sonuncu boyun tematik yapısında Aruz Koca kahraman ve anti-kahraman statülerde bulunduğu gibi, Kazan da söz konusu statülerde bulunabilmektedir. Her iki karakterin statü değişikliği Beyrek'in öldürülmesi semantemiyle ilgilidir. Beyrek'in öldürülmesi olayını yansıtan tematik yapı, koşullu olarak iki bölüme ayrılmaktadır. İlk bölümde Aruz, törenin savunucusu olarak kahraman niteliğinde tanımlanmakta, ikinci bölümde ise Beyrek'i öldüren anti-kahramana dönüşmektedir. Kazan ise tematik yapının ilk bölümünde töreye aykırı davrandığı için anti-kahraman olarak betimlenmekte, ikinci bölümde Beyrek'in öldürülmesinden sonra onun intikamını alan kahraman durumuna getirilmektedir. Denilebilir ki her iki karakter statüleri, tematik yapının bölümlerinde değişikliğe maruz kalmakta ve bu statü değişiklikleri Beyrek'in öldürülmesi olayıyla oluşmaktadır. Bu oluşum, ilk tematik yapı katmanına yansımakta ve aşağıdaki 2. şemada net olarak görülmektedir:

2. ŞEMA

\begin{tabular}{|c|c|c|}
\hline \multicolumn{2}{|c|}{ Tematik yapının ilk bölümü } & Tematik yapının ikinci bölümü \\
\hline KAZAN & Anti-kahraman & Kahraman \\
\hline ARUZ & Kahraman & Anti-kahraman \\
\hline
\end{tabular}

Tematik yapının ikinci bölümü en son dönüşüm aşaması olarak değerlendirilebilir. Aruz, tematik yapının ikinci bölümünde anti-kahramana dönüşmüş olsa da, o, aynı zamanda kahraman statüde kalmaya devam etmektedir. Bu, bir karakterin ikili statüsü, net olarak kendi statüsünü değiştirebilme yeteneğidir. Aynı statüler, etno-terminolojik dönüşüm bağlamında değerlendirildiği zaman Aruz’un Üç Ok-Boz Ok katmanında kahraman, İç Oğuz-Taş Oğuz katmanında ise ikili statüde bulunabildiği görülmektedir. Bu statüler, aşağıdaki 3. şemada şu şekilde görülmektedir: 
3. ŞEMA

\begin{tabular}{|c|c|c|}
\hline \multicolumn{2}{|c|}{ Tematik yapının ilk bölümü } & Tematik yapının ikinci bölümü \\
\hline ARUZ & Kahraman & hem anti-kahraman hem de kahraman \\
\hline
\end{tabular}

Aruz’un aynı zamanda iki statüde bulunması hususu, süreç açısından statü değişimi, epik olgunun yapısı bakımından rol değişimidir. Söz konusu karakterin önce kahraman, daha sonra anti-kahraman statüde bulunuşu, bu karakterin statü değişimiyle ilgili rolünün ve tasarlanmış işlevinin göstergesidir. Epik metinde tasarlanmış olan işlevin temelinde ise ritüelin bulunduğu söylenebilir.

\section{2. Tematik Yapının Ritüel-Mitolojik Semantiği}

Sonuncu boydaki tematik yapı, ritüel-mitolojik bağlamla ilintilidir. Bu açıdan, boyun genel yapısı yalnız işlevsellik açısından değil, aynı zamanda ritüel bağlam bakımından da değerlendirilebilir. Sonuncu boyun ritüel bir betimlemeyle başlandığı gerçeğine dayanarak denilebilir ki ritüel olgusu, doğrudan boyun giriş unsuruna dönüşmüştür. Boy başlangıcına yansımış ilk bağımsız unsurun ritüelin - peşinden ise ikinci bağımsız bir unsur (tematik yapı) gelmektedir. Genel olarak eposun on iki boyu ritüelle (yom'larla) sonlandırılır ve bu olgu, boy yapısının üçüncü bağımsız unsurunu oluşturabilmektedir. Görülmektedir ki, sonuncu boy trikotomik bir yapıya sahiptir.

Sonuncu boy girişinin ritüelden ibaret oluşu yalnızca bir olasılık gibi dikkat çekmemektedir. Tipolojik bağlama dayanarak denilebilir ki epik yapılardaki ritüel, özel bir işlevselliğe sahiptir. Putilov, Rus eposuna dayanarak yazmaktadır ki prens sarayı, bılina (kahramanlık destanları) karışımının durumunu net bir şekilde yansıtmaktadır ve epik karşıtlıkların çoğunluğu bu ortamda, daha fazla toplantı zamanı karmakarışık olmakta ve güçlerin konsantrasyonu burada ortaya çıkmaktadır. ${ }^{13}$ Dede Korkut Kitabı'nda da I., III., VII., IX. ve X. boyların başlangıcı Bayındır Hanın; II., IV., XI. ve XII. boyların giriş kısımları ise Kazan Hanın otağlar (çadırlar) kurdurup meclisler (merasim, yeme-içme, sohbet, yarış vs.) düzenletmesiyle başlamaktadır. Denilebilir ki özellikle sonuncu boya yansıyan başlangıç unsuru (ritüel), kendi işlevsel semantiği bakımından Oğuz kozmosunun aynı ortam için değişmez yapısını belli eden bir göstergedir. $\mathrm{Bu}$ tespit, mantıksal-semiyotik bağlamda varsayım niteliğinde ele alınabilir. Ancak tematik yapıdaki ritüel konumun bozulması olayı, kozmosun kaosa geçmesiyle gerçekleşmekte ve kaosun ortadan kaldırılmasıyla sona ermektedir. İşte bu husus, tespit edilen göstergenin kabul edilebilirliği anlamına gelmektedir. Özellikle, Dede Korkut Kitabı'ndaki boyların final kısımlarına yansımış “yom verme" ritüeli, Oğuz yiğitlerinin boylardaki anti-yapıyı tamamen yok etmeleri ve her boy sonunda Korkut Ata'nın ortaya çıkıp kopuz çalması olayı, onarılan Oğuz kozmosunun ritüel düzeyde de değerlendirilebileceğini göstermektedir.

Sonuncu boydaki her üç yapısal unsurun, gösterge, kabul edilebilirlik ve belirlenme gibi işlevsel kategorilerin ortaya çıkmalarına neden olduğu söylenebilir. Söz konusu boy, bir metin olarak üç unsurun işlevsel düzümü (ritüel - tematik yapı - ritüel) niteliğinde oluşmaktadır.

13 Putilov, Geroiçeskiy Epos i Deystvitelnost, 53. 
Böylelikle, tematik yapı boy yapısını yansıtmaktadır. Şöyle ki sonuncu boy gibi tematik yapının da üç unsurdan ibaret oluşu ve boyun gösterge, kabul edilebilirlik ve belirlenme kavramlarına göre yapılandırılması doğrudan tematik yapıyı da aynı şema kapsamında yapılandırmaktadır:

1. Başlangıç--------------Gösterge
2. Tematik yapt-----------Kabul edilebilirlik
3. Sonuç------------------Belirlenme

Tematik yapının genel olarak boy yapısını yinelemesi olayı, epik dünya modelindeki yapısal unsurların ritmik-yansıma ilkelerine dayanmaktadır. Bu kapsamda boy, Dede Korkut Kitabı'nın yapısal unsuru gibi, tematik yapı ise incelenen boyun yapısal unsuru niteliğinde değerlendirilebilir. Boy ile tematik yapının işlevsel ve yapısal özdeşliği ise her iki olgunun yapısında aynı invaryant (değişimsiz) şemanın bulunduğunu göstermektedir. Aynı invaryant yapı, boy bağlamında metin unsuru, tematik yapı bağlamında da olay unsuru olarak gerçekleşmektedir. Yani tematik yapı, profan (kutsal dışı) olay yapısını, boy ise kutsallıktan ibaret bir yapıyı yansıtmaktadır. Kutsal-profan nitelikli çift yapı bakımından boy yapısı da net bir sonuca ulaşmakta veya ritüel ile başlayıp ritüel ile sona ermektedir. Ancak sona ermiş olan bu yapı, belirli bir derecelenmeyi - kutsal ve kutsal olmayan aşamaları - içermektedir. Bu hususu aşağıdaki 4. şemada göstermek mümkündür:

4. ŞEMA

\begin{tabular}{|l|c|c|c|}
\hline Kutsal başlangıç ritüeli & & \multicolumn{2}{|c|}{ Kutsal son ritüeli } \\
\hline & Profan tematik yapı & & \\
\hline
\end{tabular}

On ikinci boy, Üç Ok - Boz Ok ile ilgili kutsal nitelikli ve uyulması gereken bir geleneğin

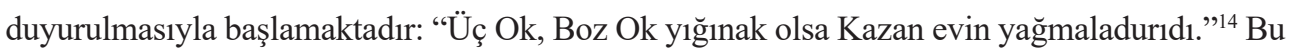
husustan sonra ritüel olgusu tematik yapıya yansımaktadır. Söz konusu yansıma sonucu epik anlatımın da doğrudan kutsal olgudan (Üç Ok - Boz Ok) profan olguya (İç Oğuz - Taş Oğuz) yansıdığı görülmektedir. Yani, Üç Ok - Boz Ok’tan neşet eden gelenek, bir sonraki törende yine icra edilmekte veya uygulanmaktadır (yağma olayı gerçekleşmekte ve törene sadece İç Oğuzlar katılmaktadır). Aslında yağma törenine katılan İç Oğuzlar, Taş Oğuzların payını da yağma etmekte ve İç Oğuz ile Taş Oğuz arasında düşmanlığın oluşmasına neden olmaktadırlar. Oluşan düşmanlık sonucu çıkan savaşta Han Kazan, Aruz'u öldürüp birliği sağlar ve tematik yapı, Kazan'ın elde ettiği zaferin kutlanmasıyla sonuçlanır. Böyle bir sonuçta profan olgunun yine kutsal olguya yansıdığı görülmektedir. Bu sonuç bağlamında Dede Korkut, "yom verme" ritüeliyle Üç Ok - Boz Ok kutsal yapısının bozulmazlığını beyan etmekte ve dolayısıyla kozmosun kaos üzerinde çaldığ 1 galebenin daima var olacağını duyurmaktadır. Bu durumda tematik yapı betimlenmesinin çeşitli terminolojik katmanlarını sıralamış olursak aşağıdaki yapı oluşabilir:

14 Gökyay, Dedem Korkudun Kitabl, 187. 


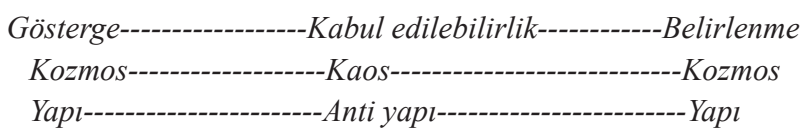

Sonuncu boy yapısı ritüel-mitolojik nitelikte olduğu için yukarıdaki şema, ritüelistik şema gibi de değerlendirilebilir. Söz konusu boy yapısı, bir varyant olarak ritüelin yapısını (ritüelmitolojik invaryantı) da yansıtmaktadır. Dikkat çeken en önemli özellik ise tematik yapının kendisinin boy yapısını yansıtmasıdır. Bu durumda invaryant-paradigma nitelikli şemaya dayanıp aşağıdaki yapı oluşturulabilir:

Invaryant-----------------------------Ritüel-mitolojik yapı
Metin varyantl---------------------Boy yaptsı
Tematik yapı varyantı---------------Tematik yapı

Böylelikle, sonuncu boyun tematik mikro düzeni, işlevsellik kazanan hususlar bakımından ritüel-mitolojik invaryantı yansıtmaktadır. Tematik yapının metin altı bağlamında da ritüelin bulunduğu görülmekte ve tematik yapının değişebilir olması dolayısıyla doğrudan ritüel olgusu ortaya çıkmaktadır. Aynı değişkenliği oluşturan karakterlerin de ritüelle ilgili oldukları dikkat çekmekte ve sonuncu boydaki tematik yapının genel olarak ritüele dayandığı tespit edilmektedir.

\section{Sonuç}

Dede Korkut Kitabı 'nın sonuncu boyu - Iç Ŏguza Taş Oğuz Asi Olup Beyrek Öldügü Boyu - göstergebilimsel-işlevsel inceleme kapsamında değerlendirilmiş ve önemli hususlar tespit edilmiştir. Ele alınıp incelenen sonuncu boydaki iki karşıt karakter (Han Kazan ve Aruz Koca), boyun tematik yapısında bulunan merkezi karakterlerdir. İlk tespit, söz konusu karakterler arasında oluşan karşıtlığın yeni karşıtlıklara ve genel olarak İç Oğuz ile Taş Oğuz arasında düşmanlık ve savaşa neden olması hususudur. Kaydedilen karşıtlık olgusunun irdelenmesi sonrası elde edilen daha bir önemli tespit ise Kalın Oğuz'un başına kimin ve hangi tirenin (Üç Ok’un mu yoksa Boz Ok'un mu) egemen olma hakkına sahip olduğunun belirlenmesidir.

Araştırmada ele alınan boydaki epik çatışmanın çözülmesinin kaçınılmaz olduğuna ilişkin hususlar değerlendirilmiş, Oğuz topluluğunda muhafaza edilen törenin önem ve etkisi üzerine görüşler aktarılmıştır. Araştırma sonucunda Oğuz topluluğundaki yağma geleneğinin bozulmasıyla Kalın Oğuz ilindeki kozmik düzenin de bozulabileceği, tematik bağlamın merkezi karakterlerinde görülen statü değişikliğinin doğrudan Beyrek'in öldürülmesi olayıyla ilgili olduğu ve boydaki tematik yapının ritüel olgusuyla ilintili bulunduğu kanısına varılmıştır. 
Hakem Değerlendirmesi: Dış bağımsız.

Çıkar Çatışması: Yazar çıkar çatışması bildirmemiştir.

Finansal Destek: Yazar bu çalıșma için finansal destek almadı̆̆ını beyan etmiștir.

Peer-review: Externally peer-reviewed.

Conflict of Interest: The author has no conflict of interest to declare.

Grant Support: The author declared that this study has received no financial support.

\section{Kaynaklar/References}

Abdulla, Kamal. Dede Korkut Kitabı'nın Poetikasına Giriş Şafak Varyantı. Çeviren Ali Duymaz. İstanbul: Ötüken Yayınları, 2020.

Gökyay, Orhan Şaik. Dedem Korkudun Kitabı. İstanbul: Kabalcı Yayınevi, 2006.

Levi-Stross, Klod. “Mif-Ritual-Genetika.” Jurnal Priroda 1, (1978): 90-106.

Levi-Stross, Klod. Strukturnaya Antropologiya. Moskva: Nauka, 1985.

Putilov, Boris Nikolayeviç. Geroiçeskiy Epos i Deystvitelnost. Leningrad: Nauka, 1988.

Terner, Viktor. Simvol i Ritual. Moskva: Nauka, 1983. 
